\title{
вMJ Global Health Successes and challenges of the millennium development goals in Ethiopia: lessons for the sustainable development goals
}

\author{
Yibeltal Assefa, ${ }^{1}$ Wim Van Damme,${ }^{2}$ Owain D Williams, ${ }^{1}$ Peter S Hill ${ }^{1}$
}

To cite: Assefa Y, Damme WV, Williams OD, et al. Successes and challenges of the millennium development goals in Ethiopia: lessons for the sustainable development goals. BMJ Glob Health 2017;2:e000318. doi:10.1136/ bmjgh-2017-000318

Received 12 February 2017 Revised 18 June 2017 Accepted 19 June 2017
CrossMark

\begin{abstract}
- Additional material is published online only. To view please visit the journal online (http://dx.doi.org/10.1136/ bmjgh-2017-000318).
\end{abstract}

${ }^{1}$ School of Public Health, The University of Queensland, Brisbane, Australia

${ }^{2}$ Department of Public Health, Institute of Tropical Medicine, Antwerp, Belgium

Correspondence to Dr Yibeltal Assefa; y.alemu@uq.edu.au

\section{ABSTRACT}

We analysed the performance of Ethiopia in achieving the health-related millennium development goals (MDGs) with the aim of acquiring lessons for the sustainable development goals (SDGs). Ethiopia achieved most of the health MDGs: a $67 \%$ reduction in under-five mortality, a $71 \%$ decline in maternal mortality ratio, a $90 \%$ decline in new HIV infections, a decrease in malaria-related deaths by $73 \%$ and a more than $50 \%$ decline in mortality due to tuberculosis. We argue that these achievements are due to implementation of a mix of comprehensive strategies within the health system and across other sectors of the government. Scaling up of interventions by disease control programmes (including the health extension programme) and strengthening of the health system have played important roles towards the achievements. These health gains could not have been realised without progress in the other MDGs: poverty reduction, education, access to safe drinking-water and peace and stability of the country. However, the gains were not equitable, with differences between urban and rural areas, among regions and socioeconomic strata. Ethiopia's remarkable success in meeting most of the targets of the health-related MDGs could be explained by its comprehensive and multisectoral approach for health development. The inequity gap remains a challenge that achieving the health-related SDGs requires the country to implement strategies, which specifically target more marginal populations and geographic areas. This also needs peace and stability, without which it is almost impossible to improve health.

\section{INTRODUCTION}

At the beginning of the new millennium, world leaders gathered at the United Nations to outline a wide-ranging vision against poverty. The vision was translated into eight goals called millennium development goals (MDGs) which became the most significant commitment ever made by world leaders for international development. Three of the eight MDGs were health goals: Goal 4 (reduce child mortality), Goal 5 (improve maternal health) and Goal 6 (combat HIV/ AIDS, malaria and other diseases). ${ }^{1}$ These

\section{Key questions}

What is already known about this topic?

- The millennium development goals (MDGs) provided a context for the establishment of significant commitments and initiatives and were associated with increased resources from development partners.

- Ethiopia implemented the MDGs through its poverty reduction and development strategies and growth and transformation plans.

What are the new findings?

- Ethiopia achieved most of the targets of the health MDGs, and these achievements were thought to be due to comprehensive strategies within the health system and across other sectors.

- However, the gains are not so equitable that there are disparities among regions and between urban and rural areas.

Reccomendations for policy

- Addressing the inequity gap, in addition to other emerging challenges such as epidemics and noncommunicable diseases, remains as a priority task during the era of the sustainable development goals (SDGs).

- Achieving the health-related SDGs requires targeted, efficient and comprehensive strategies and financing mechanisms.

goals substantially shaped the development discourse and aid the architecture in such a way that most aid agencies and civil society organisations substantially reoriented their work towards the achievement of the MDGs. ${ }^{2}$

The MDGs also provided a context for the establishment of significant commitments and initiatives globally. In Africa alone, these included the 2001 Abuja Declaration on health financing, ${ }^{3}$ the 2005 WHO African Regional Committee resolution on achieving the MDGs, ${ }^{4}$ the 2008 Ouagadougou Declaration on Primary Health Care and Health 
Table 1 Trends in under-five, infant and neonatal mortality rates in Ethiopia, 1990-2015

\begin{tabular}{lccccc}
\hline Indicators & $\mathbf{1 9 9 0}$ & $\mathbf{2 0 0 0}$ & $\mathbf{2 0 0 5}$ & $\mathbf{2 0 1 0}$ & $\mathbf{2 0 1 5}$ \\
\hline Under-five mortality rate per 1000 live births & 205 & 166 & 123 & 88 & 67 \\
Infant mortality rate per 1000 live births & 123 & 97 & 77 & 59 & 48 \\
Neonatal mortality rate per 1000 live births & 54 & 49 & 39 & 37 & 20 \\
\hline
\end{tabular}

Systems in Africa, ${ }^{5}$ the Harmonisation for Health in Africa mechanism ${ }^{6}$ and the 2008 UN Secretary-General's MDGs Africa Initiative. ${ }^{7}$

Moreover, the MDGs were associated with increased resources from development partners, providing good incentives for low-income countries to translate and operationalise the MDGs to their context. Low-income countries, including Ethiopia, tied their poverty reduction and development plans to the MDGs. ${ }^{8}$ Implementation of the MDGs has been monitored globally using 48 indicators (including 12 for the health MDGs). ${ }^{9}$ However, they were criticised that they were lacking the granularity needed to show improvements among the disadvantaged groups within societies. ${ }^{1011}$

Ethiopia implemented the MDGs through its poverty reduction and development strategies and growth and transformation plans. It was also tracking its performance and reporting on the MDGs annually. ${ }^{12}$ The paper analyses performance of Ethiopia against the health-related MDG indicators, identifies successes and challenges and pinpoints lessons for the sustainable development goals (SDGs) which are ambitious and demanding. Understanding the implications of this analysis is vital to satisfying the higher demands of the SDGs. ${ }^{13}$

\section{SUCCESSES AND CHALLENGES DURING THE ERA OF THE MDGS IN ETHIOPIA \\ MDG 4: reduce child mortality}

The under-five mortality rate per 1000 live births decreased from 205 in 1990 to 67 in 2015. Over the same time interval, the infant mortality rate declined from 123 to 48 and the neonatal mortality rate also showed a similar decline from 54 to 20 (table 1). The target for under-five mortality rate was achieved, while the targets for infant and neonatal mortality rates (reductions of $61 \%$ and $63 \%$, respectively) were just below the MDG 4 target $(67 \%) .^{14} 15$

Mortality rates were, in general, significantly higher in rural than in urban areas (114 vs 83 per 1000 live births). Children born and raised in rural areas had at least a $38 \%$ higher risk of dying prior to age five compared with their urban counterparts. Addis Ababa (AA), Harari, Dire Dawa (DD) and Tigray had under-five mortality rates less than 90 deaths per 1000 live births. On the other hand, the under-five mortality rates in Benshangul Gumuz, Afar, Gambela and Somali were more than 120 per 1000 live births (figure 1)..$^{1415}$

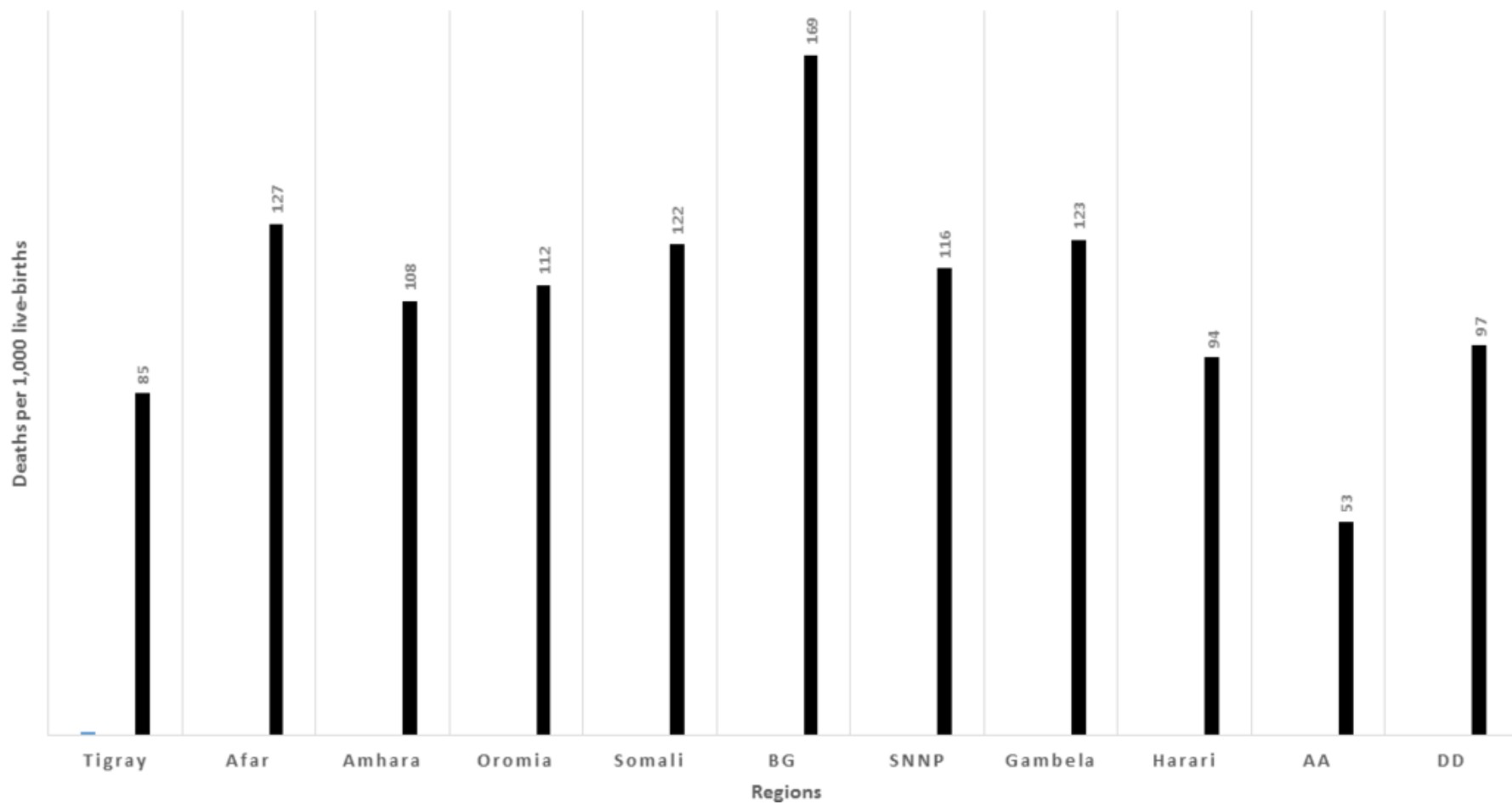

Figure 1 Under-five mortality rates in regions in Ethiopia, 2011. AA, Addis Ababa; BG, Benshangul Gumuz; DD, Dire Dawa. 
Table 2 Trends in maternal mortality ratio and reproductive health services in Ethiopia, 1990-2015

\begin{tabular}{|c|c|c|c|c|c|}
\hline Indicators & 1990 & 2000 & 2005 & 2010 & 2015 \\
\hline Maternal mortality ratio per 100000 live births & 1400 & 871 & 673 & 676 & 412 \\
\hline Contraceptive prevalence rate (any method) & $4 \%$ & $8 \%$ & $15 \%$ & $29 \%$ & $36 \%$ \\
\hline Facility births & $2 \%$ & $5 \%$ & $5 \%$ & $10 \%$ & $26 \%$ \\
\hline Skill-birth attendance & $3 \%$ & $6 \%$ & $6 \%$ & $10 \%$ & $28 \%$ \\
\hline Teenage pregnancy & - & $16.3 \%$ & $16.6 \%$ & $12 \%$ & $13 \%$ \\
\hline
\end{tabular}

Proportion of 1-year-old children immunised against measles increased from $21 \%$ in 2000 to $54 \%$ in 2015 . While $76 \%$ of children in urban areas were reported to be vaccinated for measles, only $52 \%$ of children in rural areas were vaccinated, with rates ranging from $30 \%$ in Afar to $93 \%$ in $\mathrm{AA}^{1415}$

\section{MDG 5: improve maternal health}

Maternal mortality ratio (MMR) per 100000 live births declined by $71 \%$ from 1400 in 1990 to 412 in 2015 (table 2). This was thus close to the target for MDG 5 $(75 \%)$. $^{1415}$

The percentage of women receiving one antenatal care (ANC) visit from a skilled provider (doctor, nurse or midwife) for their most recent birth had increased from $6 \%$ in 1990 to $62 \%$ in 2015 . There was marked variation between rural and urban areas and among regions. It ranged from $44 \%$ (Somali region) to $97 \%$ (AA). Rural women were less likely than urban women to have received ANC from a skilled provider $(58 \%$ and $90 \%$, respectively). Three in 10 women (32\%) had four or more ANC visits for their most recent live birth which increased from $10 \%$ in 2000 . Lower proportion of rural women $(27 \%)$ had four or more ANC visits than urban women $(63 \%)$. $^{1415}$

There had been remarkable progress in facility (excluding health posts) births from 5\% in 2000 to $26 \%$ in 2015 . But, there is a dramatic contrast in facility delivery between rural areas $(20 \%)$ and urban areas $(79 \%)$ and across regions (15\% in Afar and $97 \%$ in AA). Skilled birth attendance rate, excluding health extension workers, increased from $3 \%$ in 1990 to $28 \%$ in $2015 .{ }^{1415}$

The percentage of married women with unmet needs for family planning (FP) declined from $37 \%$ in 2000 to $22 \%$ in 2015 . The proportion of married women using modern contraceptive methods increased from $6 \%$ in 2000 to $35 \%$ in 2015 . The unmet need for FP was $24 \%$ in rural areas and $11.3 \%$ in urban areas and variable across regions at $29 \%$ in Oromia and $11 \%$ in AA. ${ }^{1415}$

\section{MDG 6: combat HIV/AIDS, malaria and other diseases HIV/AIDS}

The prevalence of HIV among pregnant women aged 15-24 years declined sharply from $12.4 \%$ in 2000 to $1.7 \%$ in 2015. Condom use among 15-49 years of age increased from $30 \%$ in 2000 to $45.5 \%$ in 2015 . Comprehensive knowledge of HIV increased from $15 \%$ in 2000 to $30.4 \%$ in $2015 .^{1415}$

The number of patients on antiretroviral therapy (ART) had increased from 39535 (less than 1\% of the total number of people living with HIV/AIDS) in $2005 / 2006$ to 393609 (54.3\% of the same) in 2015 . The number of orphans that had lost at least one parent to HIV decreased from around 535000 in 2005 to 344273 in 2015 which represents a $35.6 \%$ decline (table 3$).^{1415}$

\section{Malaria}

The incidence of malaria per 100000 population decreased from 7700 in 1990 to 1540 in 2015. Deaths due to malaria per 100000 population also decreased from 54 in 1990 to 10 in 2015. Incidence and death rates associated with malaria decreased by $73 \%$ and $81 \%$, respectively, between 1990 and 2015. The percentage of households with bed nets increased from $1 \%$ in 2000 to $64 \%$ in 2015 . Children who slept under a bed net increased from $1 \%$ in 2000 to $70 \%$ in 2015 (table 3 ). ${ }^{1415}$

\section{Tuberculosis}

The incidence of tuberculosis (TB) per 100000 population declined from 421 in 2000 to 192 in 2015 (54\% reduction). Similarly, the TB mortality rate per 100000 declined from 89 deaths in 1990 to 25 deaths in 2015 (72\% reduction) (table 3). In 2015, the national TB case detection rate was $67.3 \%$ with differences across regions, ranging from $44 \%$ in Somali region to $100 \%$ in AA and DD. TB cure rate was $78 \%$ with variable performance across regions: from $38 \%$ in Afar region to $92 \%$ in Harari region. ${ }^{14}$

In general, the achievements in MDGs in Ethiopia are in line with the global trend. Between 1990 and 2015, there were successes globally in: (1) MDG 4: child mortality had dropped by $53 \%$, (2) MDG 5: MMR declined by $43 \%^{16}$ and (3) MDG 6: the number of people on ART increased from less than 0.2 million in 2000 to 7.5 million in 2010 and more than 17 million in $2015^{17}$ and the malaria and tuberculosis mortality rate had fallen by $58 \%$ and $47 \%$, respectively. $^{1819}$

\section{HOW DID ETHIOPIA ACHIEVE THE HEALTH MDGS?}

We argue that the achievements in Ethiopia are due to implementation of a comprehensive health development 


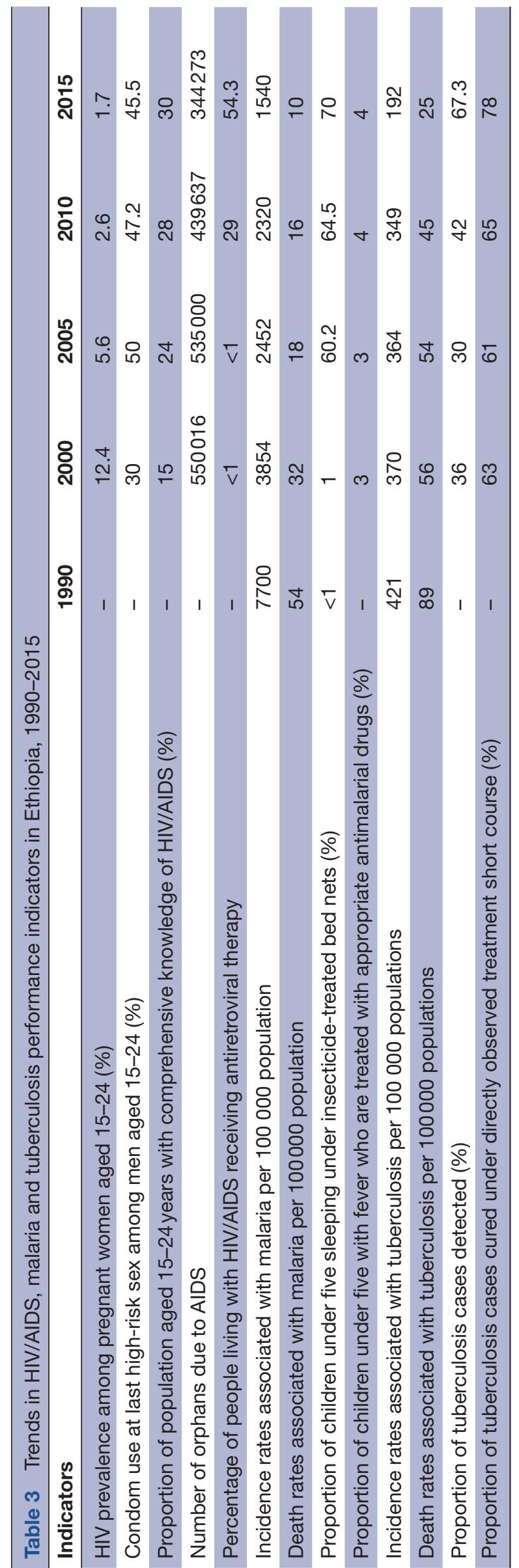

strategy which has short-term, mid-term and longterm prongs. Short-term and mid-term strategies include scaling up of interventions by disease control programmes, including community health programmes (the health extension programme). Long-term strategies include strengthening of health systems using and redirecting domestic and global health initiatives ${ }^{2021} ;(1)$ the number of health facilities increased dramatically between 2005 and 2015: health posts increased from 8528 to 16480 , health centres increased from 690 to 3562 and hospitals increased from 88 to $241^{22}$; (2) the 'flooding strategy' for human resource for health has increased the number of physicians from 2325 in 2005 to 6570 in 2015 and other paramedical cadres: the number of health extension workers reached 38000 from nil in $2000^{22}$ and (3) financing for health has also increased significantly in the country. ${ }^{23}$

The national health expenditure increased by $207 \%$ from US $\$ 522$ million in 2004/2005 to over US $\$ 1.6$ billion in 2010/2011. ${ }^{24}$ The largest increment in financing came from the development partners $(315 \%)$ and households (237\%). The government's contributions also grew by $57 \%$ over the same period. In 2010/2011, overseas development partners, households and the government contributed to $50 \%, 34 \%$ and $15.6 \%$, respectively, to the total health expenditure in the country. ${ }^{24}{ }^{25}$ National AIDS Spending Assessment also estimated that the total spending on HIV/AIDS was equivalent to US $\$ 405$ million in 2011/2012 (86\% from development partners, 13\% from public revenue and less than $1 \%$ from the private sector) ${ }^{26}$

The achievements in the health-related MDGs in Ethiopia could not have been realised without successes in the other MDGs: poverty reduction, education, access to safe drinking-water and peace and stability of the country. The proportion of people living below the absolute poverty line had decreased from $48 \%$ in 1990 to $23.4 \%$ in 2015. The total fertility rate had declined from 7.7 children per woman in 1990 to 4.6 children per woman in $2015 .^{1527}$ The proportion of households with access to piped water had increased from $18 \%$ in 2000 to $88 \%$ in $2015 .{ }^{15}$ The 'one plan, one budget and one report' approach also facilitated coordination and partnership among stakeholders (including multilateral, bilateral, private and public organisations) towards improved efficiency. ${ }^{28}$

In spite of these overall achievements in the health-related MDGs in Ethiopia, there were also challenges that would also be concerns during the era of the SDGs: (1) health financing and (2) inequity in health outcomes. Even though the government expenditure on health (as a percentage of total government expenditure) increased from $3 \%$ in 1995 to $4.9 \%$ in 2014, it is still below the Abuja commitment to spend $15 \%$ of the government budget on health. ${ }^{29}$ Per capita health expenditure also increased from US $\$ 4.5$ in 1995 to US $\$ 26.7$ in 2014. However, this is well below the US $\$ 35$ recommended by WHO in 2001 (this increased to US\$60 in 2014) to deliver essential 
healthcare in low-income countries. ${ }^{30}$ It is an indication that health is underfinanced and the government, in particular, should allocate more resources to health. There is thus a high dependency on donors for financing health, in general, and for HIV/AIDS, in particular. Household out-of-pocket expenditure on health remains high. ${ }^{31}$ Together, this makes sustainability of health financing and services delivery a serious concern in Ethiopia during the era of the SDGs.

There is a huge disparity in levels of achievement among regions, between rural and urban areas, among populations of different socioeconomic status. The gains in MDGs were not equitable that there are regions which were lagging far behind others. ${ }^{32}$ These equity gaps are due to differentials in health systems capacity and differences in socioeconomic development among regions and between urban and rural areas in the country. ${ }^{33}$ These gaps will indeed be challenges that the SDGs need to address using comprehensive strategies including the universal health coverage (UHC) ${ }^{34}$ and the social determinants of health approach. ${ }^{35}$

\section{How can Ethiopia achieve its health SDGs?}

Ethiopia has adapted the current global development agenda (SDGs) which has 17 goals, with Goal 3 focusing on health (ensure healthy lives and promote well-being for all at all ages). ${ }^{36}$ The SDGs have inherited not only the successes but also the challenges of the MDGs. It is thus strategic for Ethiopia that the success during the MDGs is sustained while it is also addressing the challenges systematically during the SDGs.

We argue that it is still commendable for the country to use a comprehensive approach: (1) strengthening the three prongs (disease control programmes, community health programmes and health systems) for health development ${ }^{37}$ (2) investing on the social determinants of health ${ }^{38} 39$ and (3) securing peace and stability in the country. ${ }^{40}$ In addition, the country needs to move towards UHC and right the inequities between urban and rural, among regions and socioeconomic status by implementing targeted interventions which should again be comprehensive, multisectoral and targeted. This requires targeted models of service delivery, increased health financing and enhanced socioeconomic status in marginalised populations lagging behind the national averages during the era of MDGs.

The equity gap cannot be resolved by implementing simply more of the same strategies that were used during the MDGs. Strategies that are directed at the areas with greatest need, including most marginalised and disadvantaged populations, should be identified and implemented. This, in addition, requires increased and sustained financing from both the government and its stakeholders. This also entails commitments to improve the social determinants of health, including education and socioeconomic conditions, in regions and populations lagging behind others. ${ }^{32}$
In addition to the unfinished agenda, such as inequities, the SDGs have also included a whole new range of health targets such as non-communicable diseases, traumas and injuries, infectious epidemic diseases (the global health security agenda $(\mathrm{GHSA}))^{41}$ and UHC. These all require more interventions, resources and commitment and better ways of implementing the interventions. There is, therefore, a need for harmonisation of these different initiatives, such as UHC and GHSA, so that they will be synergistic to each other towards the overall attainment of the health SDGs. There is thus a need for joint planning, investment, implementation and monitoring and evaluation among the different initiatives and actors. ${ }^{42}$ This is possible provided that there is political commitment, stakeholder engagement and international solidarity. ${ }^{43}$

Last, but not least, addressing the inequity gap requires a robust data system which generates granular data for geographic areas, population groups and socioeconomic status. ${ }^{44}$ Nevertheless, there is limitation in the existing data system that needs to be addressed during the SDGs which need even more robust and granular data towards meeting equity and UHC goals. The country should therefore strengthen its data systems, including routine programme monitoring, national and regional health surveys and surveillances, vital registration and cause of death verification, health systems and services research and programme evaluations. This also requires analytical capacity and culture of data use for evidence-based clinical and public health decision-making. This is possible with leadership commitment and stakeholders' motivation to invest on data systems.

\section{CONCLUSION}

Ethiopia achieved most of the health MDGs: a $67 \%$ reduction in under-five mortality, a $71 \%$ decline in MMR, a $90 \%$ decline in new HIV infections, a decrease in malaria-related deaths by $73 \%$ and a more than $50 \%$ decline in mortality due to TB. These achievements are thought to be due to a comprehensive approach (including health and other socioeconomic systems) to health development which can be a lesson that countries, even the poorest ones, can achieve unprecedented results by implementing these multidimensional strategies. The task is, however, not yet complete, as the gains are not so equitable, and much work remains to be done to address this unfinished agenda in addition to addressing other emerging challenges, such as epidemics and non-communicable diseases. If the country is to achieve its health-related SDGs, it needs to implement targeted, efficient and comprehensive strategies and financing mechanisms that will address the equity gaps inherited from the MDGs. This also requires peace and stability of the country, as it is almost impossible to develop health without it.

Contributors YA conceptualised the paper, conducted the data collection and analysis and led the manuscript writing. WVD and PSH advised on the data analysis and commented on successive drafts of the manuscript. ODW commented on 
successive drafts of the manuscript. All the authors critically revised the content of the paper, approved the final version and agreed to be accountable for all aspects of the work.

\section{Competing interests None declared.}

Provenance and peer review Not commissioned; externally peer reviewed.

Open Access This is an Open Access article distributed in accordance with the Creative Commons Attribution Non Commercial (CC BY-NC 4.0) license, which permits others to distribute, remix, adapt, build upon this work non-commercially, and license their derivative works on different terms, provided the original work is properly cited and the use is non-commercial. See: http://creativecommons.org/ licenses/by-nc/4.0/

(C) Article author(s) (or their employer(s) unless otherwise stated in the text of the article) 2017. All rights reserved. No commercial use is permitted unless otherwise expressly granted.

\section{REFERENCES}

1. United Nations. United Nations Millennium Declaration, 2000UN New Yorkhttp://www.un.org/millennium/declaration/ares552e.htm.

2. The Global FundGlobal fund overview. http://www.theglobalfund. org/en/overview/.

3. World Health OrganizationThe Abuja declaration: ten years on. Geneva, Switzerland: WHO , 2011. http://www.who.int/ healthsystems/publications/abuja_report_aug_2011.pdf?ua=1.

4. World Health Organization. Resolution AFR/RC55/R2, achieving the health millennium development goals: situation analysis and perspectives in the African region. Brazzaville: World Health Organization, Regional Office for Africa, 2005. (AFR/RC55/20).

5. World Health Organization. Resolution AFR/RC58/R3, the Ouagadougou declaration on Primary Health Care and Health Systems in Africa: achieving better health for Africa in the new millennium. Brazzaville: World Health Organization, Regional Office for Africa, 2008. (AFR/RC58/20).

6. UNICEF. Harmonization for health in Africa: an action framework https://www.unicef.org/wcaro/HHA_Action_Framework_en.pdf.

7. United Nations. Africa's development needs: state of implementation of various commitments, challenges and the way forward. UN New York, 2008. http://www.un.org/ga/president/62/ThematicDebates/ adn/TheGleneaglesScenario.pdf.

8. Ministry of Finance and Economic Development. Ethiopia: building on progress a plan for accelerated and sustained development to end poverty (PASDEP), (2005/06-2009/10). Addis Ababa Ethiopia: MoFED, 2006. http://ethioagp.org/download/AGP-AMDe/PASDEP. pdf.

9. UNDP. Indicators for monitoring the millennium development goals definitions rationale concepts and sources. United Nations; New York, 2003. http://docplayer.net/21179513-Indicators-for-monitoringthe-millennium-development-goals-definitions-rationale-conceptsand-sources-united-nations.html.

10. The World Bank. Who would gain most from efforts to reach the millennium development goals for health? An inquiry into the possibility of progress that falls to reach the poor. Washington: WB, 2002. http://siteresources.worldbank.org/INTPAH/Resources/ Publications/Recent-Papers/13920_gwatkin1202.pdf.

11. World Health Organization. Health in 2015: from MDGs, millennium development goals to SDGs, sustainable development goals. 20 Avenue Appia, 1211 Geneva 27, Switzerland: World Health Organization, 2015. http://apps.who.int/iris/bitstream/10665/200009/ 1/9789241565110_eng.pdf?ua $=1$.

12. National Planning Commission and the United Nations in Ethiopia Millennium development goals report 2014 Ethiopia: assessment of Ethiopia's progress towards the MDGs. Addis Ababa, Ethiopia: NPC, 2015. http://www.undp.org/content/dam/ethiopia/docs/ EthiopiaMDG\%202014\%20Final\%20final.pdf.

13. UN. The sustainable development agenda. http://www.un.org/ sustainabledevelopment/development-agenda/.

14. Central Statistical Authority. Ethiopian demographic and health survey 2011. Addis Ababa, Ethiopia: CSA, 2011. https://dhsprogram. com/pubs/pdf/FR255/FR255.pdf.

15. Central Statistical Authority. Ethiopian demographic and health survey 2016. Addis Ababa, Ethiopia: CSA, 2016. https://dhsprogram. com/pubs/pdf/SR191/SR191.pdf.

16. United Nations. The millennium development goals report. New York: UN, 2015. http://www.undp.org/content/dam/undp/library/MDG/ english/UNDP_MDG_Report_2015.pdf.
17. United Nations Programme on HIV/AIDS. Global AIDS update. Geneva, Switzerland: UNAIDS, 2016. http://www.unaids.org/sites/ default/files/media_asset/global-AIDS-update-2016_en.pdf.

18. World Health Organization. World malaria report 2015. Geneva, Switzerland: WHO, 2016. http://apps.who.int/iris/bitstream/10665/ 200018/1/9789241565158_eng.pdf.

19. World Health Organization. Global tuberculosis report. Geneva, Switzerland: WHO, 2015. http://apps.who.int/iris/bitstream/10665/ 191102/1/9789241565059 eng.pdf.

20. Federal Ministry of Health of Ethiopia Health Sector Development Program IV 2010/11 - 2014/15. Addis Ababa, Ethiopia: FMOH, 2011. http://phe-ethiopia.org/admin/uploads/attachment-721-HSDP\% 20IV\%20Final\%20Draft\%2011Octoberr\%202010.pdf.

21. Ethiopian Public Health Institute. Countdown to a healthier Ethiopia: building on successes to accelerate newborn survival. Addis Ababa, Ethiopia: EPHI, 2015. https://www.rbfhealth.org/resource/ countdown-healthier-ethiopia-building-successes-acceleratenewborn-survival.

22. Federal Ministry of Health of Ethiopia Annual performance report 2014/15; Health Sector Development Program IV. Addis Ababa, Ethiopia, 2015. file:///C:/Users/User/Downloads/Annual\% 20Performance\%20Report\%202015.pdf.

23. Federal Democratic Republic of Ethiopia Ministry of Health. Ethiopia's first national health accounts report, 2001 Addis Ababa, Ethiopia: FMOH, 2014. https://www.hfgproject.org/wp-content/ uploads/2014/04/Ethiopia-Main-NHA-Report.pdf.

24. Federal Ministry of Health of Ethiopia Ethiopia's second national health accounts report, 2001. Addis Ababa, Ethiopia: FMOH, 2003. http://www.ethiopianreview.com/pdf/001/NHA2.PDF.

25. Federal Ministry of Health of Ethiopia Ethiopia's fourth national health accounts, 2007/2008. Addis Ababa, Ethiopia: FMOH, 2010. http:// apps.who.int/nha/country/eth/ethiopia nha 4.pdf.

26. Federal HIV/AIDS Prevention and Control Office. Ethiopian National AIDS Spending Assessment (NASA) report EFY 2004, 2011/12. Addis Ababa, Ethiopia: FHAPCO, 2013. http://files.unaids.org/en/ media/unaids/contentassets/documents/data-and-analysis/tools/ nasa/ethiopia 2011 en.pdf.

27. Central Statistical Authority. Ethiopian demographic and Health Survey 2000. Addis Ababa, Ethiopia: CSA, 2001. http://dhsprogram. com/pubs/pdf/FR118/FR118.pdf.

28. Federal Ministry of Health of Ethiopia. The HSDP harmonization manual (HHM). First Edition. Addis Ababa, Ethiopia: FMOH, 2007. file:///C:/Users/User/Downloads/hsdp-harmonization-manual.pdf

29. World Health Organization. How much should countries spend on health? Geneva, Switzerland:WHO2003. http://www.who.int/health financing/en/how_much_should_dp_03_2.pdf.

30. World Health Organization. Health financing WHO, 2014. http:// gamapserver.who.int/gho/interactive_charts/health_financing/atlas. $\mathrm{html}$ ? indicator=i2.

31. World Health Organization. Health financing: out-of-pocket expenditure as a percentage of private expenditure on health (\%) WHO, 2014

32. Federal Ministry of Health of Ethiopia Health Sector transformation plan, 2015/16-2019/20. Addis Ababa, Ethiopia: FMOH, 2015.

33. Ethiopian Public Health Institute. Ethiopia service provision assessment plus survey 2014. Addis Ababa, Ethiopia: EPHI, 2015. https://www.washinhcf.org/fileadmin/user_upload/documents/ Ethiopia_SPA-_Key-findings_Aug2015.pdf.

34. World Health Organization. The world health report: health systems financing: the path to universal coverage. Geneva, Switzerland: WHO, 2010. http://apps.who.int/iris/bitstream/10665/44371/1/ 9789241564021_eng.pdf.

35. Commission on Social Determinants of Health. Closing the gap in a generation: health equity through action on the social determinants of health. Final report of the commission on social determinants of health: WHO Geneva, Switzerland, 2008.

36. National Planning Commission, The Federal Democratic Republic of Ethiopia. The second growth and transformation plan (GTP II), 2015/16-2019/20: NPC Addis Ababa, Ethiopia, 2016. http:// dagethiopia.org/new/docstation/com_content.article/100/gtpii_ english_translation_final_june_21_2016.pdf.

37. Admasu K-B. Designing a resilient National health system in Ethiopia: the role of leadership. Health Systems \& Reform. In Press. 2016;2:182-6.

38. Braveman P, Gottlieb L. The social determinants of health: it's time to consider the causes of the causes. Public Health Rep 2014:129:19-31.

39. World Health Organization. Social determinants of health: the solid facts.. http://www.euro.who.int/_data/assets/pdf_file/0005/98438/ e81384.pdf. 
40. CSIS, Centre for Strategic and International Studies. Imperiling progress: how Ethiopia's response to political unrest could undermine its health gains, 2016. https://csis-prod.s3. amazonaws.com/s3fs-public/publication/161103_Fleischman ImperilingProgress_Web.pdf.

41. Global Health Security Agenda. Advancing the global health security agenda: progress and early impact from U.S. investment. https:// www.ghsagenda.org/docs/default-source/default-document-library/ ghsa-legacy-report.pdf?sfvrsn=12.

42. Ooms G, Beiersmann C, Flores W, et al. Synergies and tensions between universal health coverage and global health security: why we need a second? Maximizing positive synergies? Initiative. BMJ Glob Health 2017;2:e000217.

43. United Nations. Partnerships key to implementing new sustainable development agenda, speakers stress as General Assembly Summit enters second day. https://www.un.org/press/en/2015/ga11690.doc. $\mathrm{htm}$.

44. Development Initiatives. The data revolution and monitoring of the SDGs: the case of data on maternal mortality. http://devinit.org/post/ data-revolution-monitoring-sdgs-case-data-maternal-mortality/. 